\title{
The effect of obesity on perioperative morbidity in oblique lumbar interbody fusion
}

\author{
Zhuo Xi, MD, ${ }^{1,4}$ Shane Burch, MD, ${ }^{2}$ Praveen V. Mummaneni, MD, ${ }^{1}$ Rory Richard Mayer, MD, ${ }^{1}$ \\ Charles Eichler, MD, ${ }^{3}$ and Dean Chou, MD ${ }^{1}$
}

Departments of ${ }^{1}$ Neurological Surgery and ${ }^{2}$ Orthopedic Surgery, and ${ }^{3}$ Division of Vascular Surgery, University of California, San Francisco, California; and "Department of Neurosurgery, Shengjing Hospital of China Medical University, Shenyang, Liaoning, China

OBJECTIVE Obese patients have been shown to have longer operative times and more complications from surgery. However, for obese patients undergoing minimally invasive surgery, these differences may not be as significant. In the lateral position, it is thought that obesity is less of an issue because gravity pulls the visceral fat away from the spine; however, this observation is primarily anecdotal and based on expert opinion. The authors performed oblique lumbar interbody fusion (OLIF) and they report on the perioperative morbidity in obese and nonobese patients.

METHODS The authors conducted a retrospective review of patients who underwent OLIF performed by 3 spine surgeons and 1 vascular surgeon at the University of California, San Francisco, from 2013 to 2018. Data collected included demographic variables; approach-related factors such as operative time, blood loss, and expected temporary approachrelated sequelae; and overall complications. Patients were categorized according to their body mass index (BMI). Obesity was defined as a $\mathrm{BMI} \geq 30 \mathrm{~kg} / \mathrm{m}^{2}$, and severe obesity was defined as a BMl $\geq 35 \mathrm{~kg} / \mathrm{m}^{2}$.

RESULTS There were 238 patients (95 males and 143 females). There were no significant differences between the obese and nonobese groups in terms of sex, levels fused, or smoking status. For the entire cohort, there was no difference in operative time, blood loss, or complications when comparing obese and nonobese patients. However, a subset analysis of the 77 multilevel OLIFs that included L5-S1 demonstrated that the operative times for the nonobese group was $223.55 \pm 57.93$ minutes, whereas it was $273.75 \pm 90.07$ minutes for the obese group $(p=0.004)$. In this subset, the expected approach-related sequela rate was $13.2 \%$ for the nonobese group, whereas it was $33.3 \%$ for the obese group $(p=0.039)$. However, the two groups had similar blood loss $(p=0.476)$ and complication rates $(p=0.876)$.

CONCLUSIONS Obesity and morbid obesity generally do not increase the operative time, blood loss, approach-related sequelae, or complications following OLIF. However, obese patients who undergo multilevel OLIF that includes the L5S1 level do have longer operative times or a higher rate of expected approach-related sequelae. Obesity should not be considered a contraindication to multilevel OLIF, but patients should be informed of potentially increased morbidity if the L5-S1 level is to be included.

https://thejns.org/doi/abs/10.3171/2020.1.SPINE191131

KEYWORDS OLIF; obesity; pre-psoas; ante-psoas; oblique lumbar interbody fusion; lateral lumbar interbody fusion

A CCORDING to the World Health Organization, obesity (defined as body mass index [BMI] $\geq 30 \mathrm{~kg} /$ $\mathrm{m}^{2}$ ) is now a major public health issue, with an estimated one-third of American adults classified as overweight or obese. ${ }^{1,2}$ The annual economic impact of obesity ranges from $\$ 147$ billion to nearly $\$ 210$ billion, with obese adults using $42 \%$ more of the direct healthcare costs than adults who are nonobese. ${ }^{1,2}$ Obesity has also been associated with chronic diseases such as diabetes and cardiovascular pathology. It is also considered to be a potential contributor to lumbar stenosis and disc herniations. ${ }^{3,4}$ Because of the changing demographics of the modern world, spine surgeons are treating more obese patients, and obesity is an important risk factor that cannot be ignored. It has been

ABBREVIATIONS ALIF = anterior lumbar interbody fusion; BMI = body mass index; LLIF = lateral lumbar interbody fusion; MIS = minimally invasive surgery; OLIF = oblique lumbar interbody fusion.

SUBMITTED September 30, 2019. ACCEPTED January 27, 2020.

INCLUDE WHEN CITING Published online March 27, 2020; DOI: 10.3171/2020.1.SPINE191131. 
shown that obese patients undergoing open surgery have increased blood loss, higher complication rates, and longer operative times. ${ }^{5}$ However, for obese patients undergoing minimally invasive surgery (MIS), these differences may not be significant. . $^{5-9}$

Oblique lumbar interbody fusion (OLIF) is a type of a minimally invasive lumbar interbody fusion that accesses the spine anterior to the psoas instead of using a transpsoas approach. ${ }^{10-13}$ Because, in OLIF, the patient is placed in a lateral position, the abdominal contents shift to the contralateral side, away from the spine. This position is thought to require less visceral manipulation compared to that needed in the supine position. However, this thinking is primarily anecdotal and based on expert opinion, and to our knowledge, there has been no report on the effect of obesity on OLIF. We evaluated the effects of obesity on the perioperative morbidity of OLIF.

\section{Methods \\ Study Population}

The authors performed a retrospective medical records review of patients in whom OLIF was performed by 3 spine surgeons and 1 vascular surgeon at the University of California, San Francisco, from 2013 to 2018. The study was approved by the IRB, and patient consent was not necessary for this retrospective research. Inclusion criteria were as follows: age $\geq 18$ years, OLIF from L1 to $\mathrm{S} 1$, degenerative conditions of the lumbar spine (including deformity and spondylolisthesis), and available medical records to capture patient demographics and perioperative morbidity. Patients were excluded if they had a tumor, infection, trauma, or incomplete follow-up data. Patients were defined as obese if their BMI was $\geq 30 \mathrm{~kg} / \mathrm{m}^{2}$ and nonobese if their BMI was $<30 \mathrm{~kg} / \mathrm{m}^{2}$. A subanalysis of patients with BMI $\geq 35 \mathrm{~kg} / \mathrm{m}^{2}$ (severely obese) was also performed..$^{14}$ Data collected were demographic variables and approach-related factors such as operative time, blood loss, and complications. All complications-regardless of type-were recorded. The complications were those that were related to the OLIF procedure itself, expected, selfresolving sequelae related to the OLIF approach, and others that were not related to the surgical approach. Operative times were calculated as skin-to-skin surgical times during the OLIF, not including anesthesia induction, positioning, or posterior surgery. Data were collected by a fully trained attending spine neurosurgeon. "Perioperative" was defined as the time period from surgery to 90 days after surgery. Categorical variables were presented as numbers, and continuous variables were presented as means with standard deviations. Independent-sample t-tests and chisquare tests were used to evaluate differences. Values of $\mathrm{p}<0.05$ were considered statistically significant, and statistical analyses were performed using SPSS version 17.0 software (SPSS Inc.).

\section{Surgical Technique}

The patient was placed in the right lateral decubitus position because OLIF can only be performed from the left side in order to avoid the vena cava. If L5-S1 was included, the L1-5 portion was performed (without vas- cular surgery) before or after L5-S1, depending on the availability of the vascular surgeon to access L5-S1. For L5-S1, the disc space was marked out prior to incision using fluoroscopy, and a horizontal line relative to the L5S1 disc space was drawn on the skin. The incision was drawn approximately 2 finger breadths anterior to the iliac crest. After making the skin incision, the dissection was then carried through the external oblique, internal oblique, and transversus abdominis; these which were all bluntly separated in the direction of their fibers. The retroperitoneal space was established, and using blunt dissection, the peritoneum was mobilized toward the contralateral side. Dissection was then carried out between the right and left iliac veins, the middle sacral vessels were divided, the prevertebral space was established, and exposure of the L5S1 disc was obtained. The surgical level was confirmed with the use of fluoroscopy.

For the L1-5 portion, a percutaneous reference arc was placed into the left iliac crest through a separate stab incision. Intraoperative CT scans were obtained (O-Arm, Medtronic), and StealthStation navigation (Medtronic) was registered with the acquired images. A skin incision was made in an oblique fashion approximately $5 \mathrm{~cm}$ anterior to the midpoint of the lumbar vertebrae. The dissection was carried down through the external oblique, internal oblique, and transversus abdominis until retroperitoneal fat was identified. The navigational probe was then docked at the appropriate disc space anterior to the psoas. Dilators were placed, and the minimally invasive retractors were placed. The oblique lumbar interbody fusion was carried out in a standard fashion ${ }^{15}$ (Figs. 1 and 2).

\section{Results}

\section{Analysis of the Entire Cohort of 238 Patients}

We identified 282 OLIF patients; 38 patients were either lost to follow-up or had insufficient follow-up data (see flowchart in Supplemental Fig. 1). Six other patients had a diagnosis of tumor or trauma, and so they, too, were excluded. A total of 238 patients (95 males and 143 females) who met inclusion criteria were included in this study. There were 77 patients who had fusion both at L5-S1 and at one or more levels at L1 -5 during the same surgery. There were 24 patients who had surgery at L5-S1 only and 137 patients who had surgeries between L1 and L5 only, exclusive of L5-S1. The mean follow-up for the nonobese group was $16.65 \pm 11.63$ months, and for the obese group it was 17.30 \pm 10.15 months $(\mathrm{p}=0.669)$. The mean age in the obese group was $60.73 \pm 13.94$ years, and in the nonobese group it was $64.50 \pm 11.86$ years $(\mathrm{p}=0.029)$. There was no significant difference between the obese and nonobese groups in terms of sex $(p=0.971)$, mean number of anterior fusion levels $(p=0.431)$, or smoking status $(p=0.710)$. There was no difference in surgical time $(\mathrm{p}=0.335)$ or blood loss $(\mathrm{p}$ $=0.435$ ) between obese and nonobese patients. There were 83 patients in the obese group (BMI $\geq 30 \mathrm{~kg} / \mathrm{m}^{2}$ ), and 6 (7.2\%) had complications. There were 155 patients in the nonobese group, and $11(7.1 \%)$ had complications $(\mathrm{p}=$ 0.970). There was no difference in temporary approachrelated sequelae between the nonobese group (13.5\%) and the obese group (19.3\%) $(\mathrm{p}=0.245)($ Tables 1 and 2). 

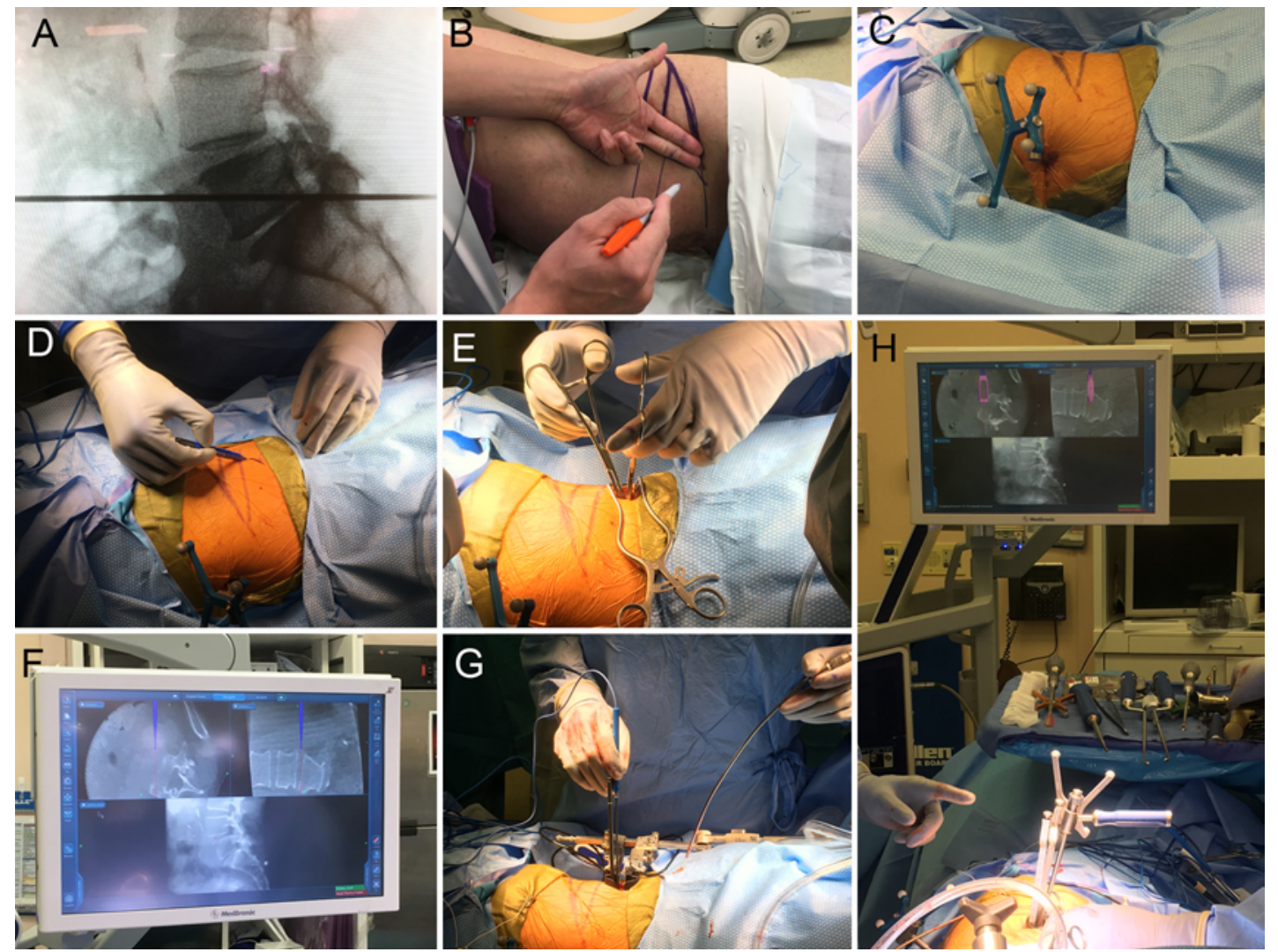

FIG. 1. Incision planning and cage positioning after L4-S1 OLIF. A: The L5-S1 disc space was marked out using fluoroscopy. B: External markings demonstrate the incision for the L5-S1 OLIF. C: A reference arc was placed into the iliac crest via a small incision. D: The L4-5 incision was planned $5 \mathrm{~cm}$ anterior to the lateral mid-disc space. E: Exposure of the L4-5 disc space. F: Navigating down to the disc space. G: Neuromonitoring to evaluate for surrounding nerves. H: Cage insertion under navigation. Figure is available in color online only.

\section{Subgroup Analysis of Severely Obese Patients With BMI $\geq 35 \mathrm{~kg} / \mathrm{m}^{2}$}

A subgroup analysis of patients was performed in patients with $\mathrm{BMI}<30$ versus $\mathrm{BMI} \geq 35 \mathrm{~kg} / \mathrm{m}^{2}$. There were 37 patients in the group with a BMI $\geq 35 \mathrm{~kg} / \mathrm{m}^{2}$, and 1 patient $(2.7 \%)$ had a complication. There were 155 patients in the group with a BMI $<30 \mathrm{~kg} / \mathrm{m}^{2}$, and $11(7.1 \%)$ of them had complications $(\mathrm{p}=0.544)$. There were no significant differences in surgical time $(\mathrm{p}=0.077)$, blood loss $(\mathrm{p}=$ $0.605)$, mean number of anterior levels fused $(p=0.534)$, or complications $(\mathrm{p}=0.306)$ between the BMI $\geq 35$ and BMI $<30 \mathrm{~kg} / \mathrm{m}^{2}$ groups. There was no difference in expected approach-related sequelae between the nonobese group $(13.5 \%)$ and the severely obese group $(13.5 \%)(\mathrm{p}=$ 0.996) (Table 3).

\section{Subgroup Analysis of Patients Undergoing at Least One Level of OLIF From L1 to L5 and Also at L5-S1}

We performed a subgroup analysis of 77 patients who underwent OLIF at L5-S1 in addition to another level between L1 and L5. Of these, 24 patients were obese, and 53 patients were nonobese (Table 4). The mean follow-up duration in the nonobese group was $14.15 \pm 9.79$ months, and in the obese group it was $18.88 \pm 9.97$ months $(\mathrm{p}=$ $0.055)$. There were no significant differences between two groups in terms of age $(p=0.116)$, sex $(p=0.092)$, mean number of anterior levels fused $(\mathrm{p}=0.955)$, or smoking status $(\mathrm{p}=0.424)$. The mean blood loss in the nonobese group was $101.42 \pm 109.68 \mathrm{ml}$, and in the obese group it was $84.382 \pm 57.02 \mathrm{ml}(\mathrm{p}=0.476)$. The mean operative time in the nonobese group was $223.55 \pm 57.93$ minutes, whereas in the obese group it was $273.75 \pm 90.07$ minutes $(\mathrm{p}=0.004)$. Obese patients also had more approachrelated sequelae (33.3\%) than nonobese patients $(13.2 \%)$ $(\mathrm{p}=0.039)$. There was no difference in complication rates between the nonobese group (9.4\%) and the obese group $(8.3 \%)(\mathrm{p}=0.876)$.

\section{Subgroup Analysis of Patients With OLIF at L5-S1 Only}

In a subgroup analysis of 24 patients who underwent OLIF at L5-S1 only, there were 9 obese patients and 15 nonobese patients. There were no significant differences between two groups in terms of age $(\mathrm{p}=0.525)$, sex ( $\mathrm{p}$ $=0.728)$, follow-up time $(\mathrm{p}=0.733)$, or smoking status $(\mathrm{p}=0.572)$. The mean blood loss in the nonobese group was $83.33 \pm 52.33 \mathrm{ml}$, and it was $55.56 \pm 16.67 \mathrm{ml}$ in the obese group $(\mathrm{p}=0.139)$. The mean operative time in the nonobese group was $164.93 \pm 70.35$ minutes, and it was $169.56 \pm 73.18$ minutes in the obese group $(p=0.879)$. There was no difference in approach-related sequelae $(\mathrm{p}$ 

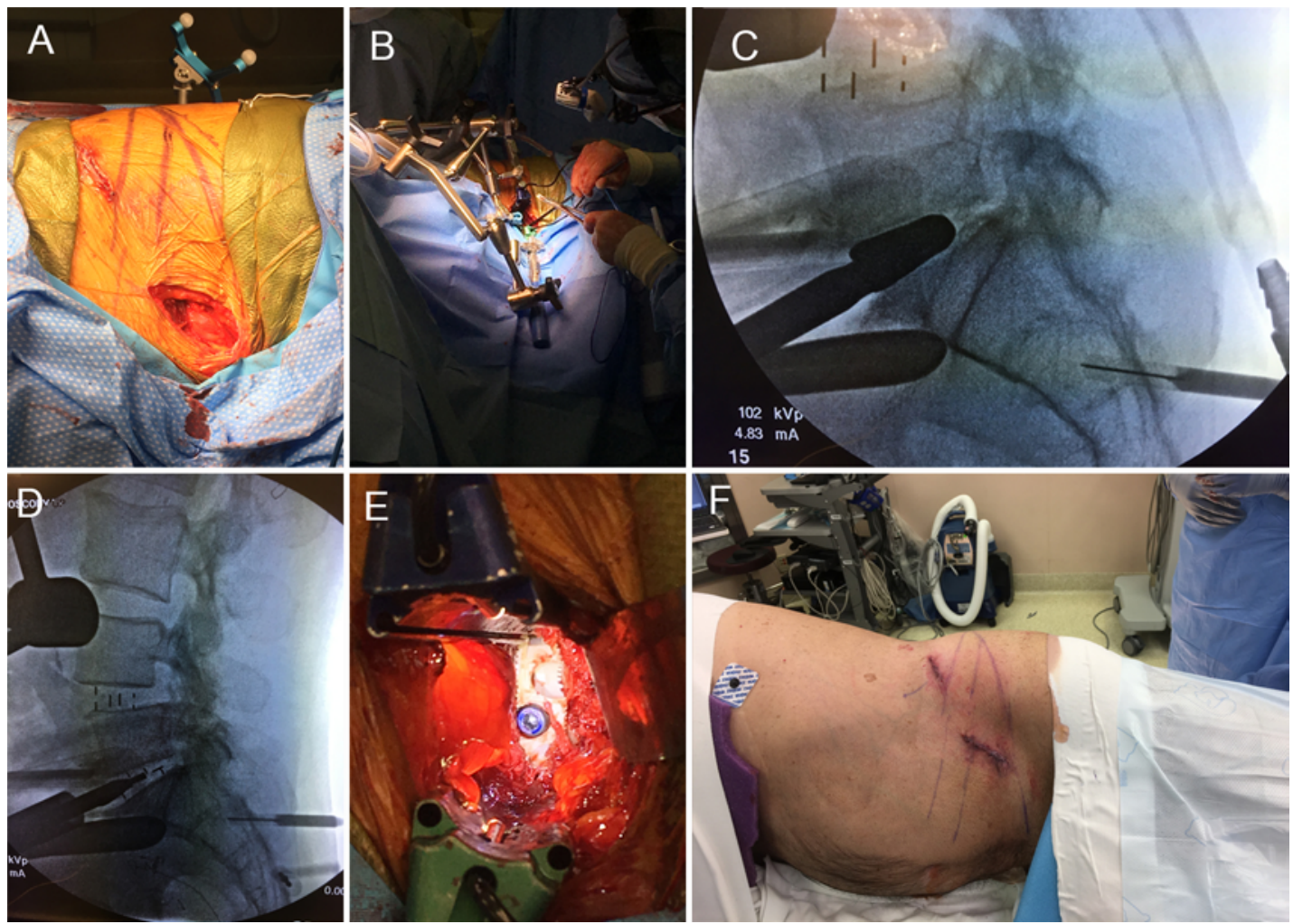

FIG. 2. An L5-S1 OLIF and the relationship between the L5-S1 and L4-5 incisions. A: The L5-S1 incision. B: Accessing the L5-S1 level. C: Preparation of the L5-S1 disc. D: Confirmation of proper cage position with fluoroscopy. E: An intraoperative view of the cage placed during the L5-S1 OLIF. F: The relationship between the L5-S1 and L4-5 incisions. Figure is available in color online only.

$=0.265)$ or complication rates $(p=0.088)$ between the groups (Table 5).

\section{Subgroup Analysis of Patients With OLIF Between L1 and L5 Without L5-S1}

There were 137 patients who underwent OLIF procedures performed between L1 and L5 that excluded the L5-S1 level. Of these, 50 patients were obese, and 87 patients were nonobese. The mean follow-up time in the nonobese group was $18.14 \pm 12.87$ months, and it was $16.86 \pm$ 10.47 months in the obese group $(\mathrm{p}=0.551)$. There were no significant differences between the obese and nonobese groups in terms of age $(p=0.152)$, sex $(p=0.155)$, mean number of anterior levels fused $(\mathrm{p}=0.717)$, or smoking status $(\mathrm{p}=0.414)$. The mean operative time for the obese group was $160.34 \pm 66.68$ minutes, whereas it was $161.55 \pm$ 71.62 minutes in the nonobese group $(\mathrm{p}=0.922)$. The mean blood loss was $87.60 \pm 65.91 \mathrm{ml}$ in the obese group and $87.76 \pm 86.75 \mathrm{ml}$ in the nonobese group $(\mathrm{p}=0.991)$. There were no differences in approach-related sequelae between the obese group (12.0\%) and the nonobese group (14.9\%) $(\mathrm{p}=0.631)$. The complication rates were comparable between the two groups, with a $4.0 \%$ rate in the obese group and $5.7 \%$ rate in the nonobese group $(\mathrm{p}=0.655)$ (Table 6).

\section{Discussion}

Obesity has been reported to be associated with degen- erative lumbar changes, spinal stenosis, and disc herniations. ${ }^{3,4}$ Because of the prevalence of obesity in modern society, it is important to clarify how obesity impacts treatment outcomes after spinal surgery. It has been reported that obesity appears to be associated with longer operative times, greater blood loss, and a higher risk of surgical site infections compared to nonobese patients undergoing open spinal surgery. ${ }^{6,7}$ Abbasi and Grant demonstrated that obesity was associated with increased surgical time and blood loss in transforaminal lumbar interbody fusion but not in OLIF. ${ }^{16} \mathrm{~A}$ review by Goyal et al. analyzed 32 studies (23,415 lumbar spine surgery patients), and they found that obese patients undergoing open spine surgery had higher blood loss, longer operative times, and higher reoperation rates than nonobese patients. However, while they did not find a difference in operative times and blood loss between obese and nonobese patients undergoing minimally invasive spine surgery, they did find that obese patients had longer operative times for MIS. ${ }^{5}$ Lingutla et al. reported similar results in a 17-study metaanalysis, showing that obese patients had greater intraoperative blood loss and longer operative time; however, pain and functional outcome scores were similar to those of nonobese patients. They also found that the primary postoperative complication in open spine surgery was surgical site infections in obese patients. ${ }^{8}$ These two large studies have shown that in open spine surgery, obesity may be associated with higher blood loss, longer operative times, 
TABLE 1. Demographic and procedural data of nonobese and obese patients

\begin{tabular}{|c|c|c|c|}
\hline Variable & $\begin{array}{c}\text { Nonobese (BMl } \\
<30, n=155)\end{array}$ & $\begin{array}{l}\text { Obese (BMl } \\
\geq 30, n=83)\end{array}$ & $\begin{array}{c}\mathrm{p} \\
\text { Value }\end{array}$ \\
\hline Age & $64.50 \pm 11.86$ & $60.73 \pm 13.94$ & 0.029 \\
\hline Sex & & & 0.971 \\
\hline Male & 62 & 33 & \\
\hline Female & 93 & 50 & \\
\hline Smoker & & & 0.710 \\
\hline No & 144 & 76 & \\
\hline Yes & 11 & 7 & \\
\hline Follow-up time (mos) & $16.65 \pm 11.63$ & $17.30 \pm 10.15$ & 0.669 \\
\hline Surgical time (mins) & $183.08 \pm 72.84$ & $194.13 \pm 89.41$ & 0.335 \\
\hline $\mathrm{EBL}(\mathrm{ml})$ & $92.00 \pm 92.53$ & $83.19 \pm 60.26$ & 0.435 \\
\hline \multicolumn{4}{|l|}{ No. of anterior levels fused } \\
\hline 1 & 67 & 42 & \\
\hline 2 & 53 & 21 & \\
\hline 3 & 15 & 13 & \\
\hline 4 & 19 & 7 & \\
\hline 5 & 1 & 0 & \\
\hline $\begin{array}{l}\text { Mean no. of anterior levels } \\
\text { fused }\end{array}$ & $1.93 \pm 1.039$ & $1.82 \pm 0.99$ & 0.431 \\
\hline Approach-related sequelae & & & 0.245 \\
\hline No & $134(86.5 \%)$ & $67(80.7 \%)$ & \\
\hline Yes & $21(13.5 \%)$ & $16(19.3 \%)$ & \\
\hline Complications & & & 0.970 \\
\hline No & $144(82.9 \%)$ & $77(82.8 \%)$ & \\
\hline Yes & $11(7.1 \%)$ & $6(7.2 \%)$ & \\
\hline
\end{tabular}

Values are presented as the number (\%) or as the mean \pm SD. EBL $=$ estimated blood loss.

and higher complication rates. However, these differences became less pronounced in obese patients undergoing MIS. ${ }^{5-7}$

In our study, there were no significant differences in operative times, blood loss, or complications when comparing patients with $\mathrm{BMI} \geq 30 \mathrm{~kg} / \mathrm{m}^{2}$ and patients with $\mathrm{BMI}<30 \mathrm{~kg} / \mathrm{m}^{2}$ when considering the entire OLIF cohort.
TABLE 3. Demographic and procedural data for nonobese and severely obese patients

\begin{tabular}{|c|c|c|c|}
\hline Variable & $\begin{array}{c}\text { Nonobese } \\
(\mathrm{BMI}<30 \\
n=155)\end{array}$ & $\begin{array}{l}\text { Severely Obese } \\
\qquad \begin{array}{c}(B M I \geq 35 \\
n=37)\end{array}\end{array}$ & $\begin{array}{c}p \\
\text { Value }\end{array}$ \\
\hline Age & $64.50 \pm 11.86$ & $58.92 \pm 14.11$ & 0.014 \\
\hline Sex & & & 0.143 \\
\hline Male & 62 & 10 & \\
\hline Female & 93 & 27 & \\
\hline Smoker & & & 0.832 \\
\hline No & 144 & 34 & \\
\hline Yes & 11 & 3 & \\
\hline Follow-up time (mos) & $16.65 \pm 11.63$ & $19.97 \pm 10.63$ & 0.114 \\
\hline Surgical time (mins) & $183.08 \pm 72.84$ & $208.00 \pm 98.34$ & 0.084 \\
\hline $\mathrm{EBL}(\mathrm{ml})$ & $92.00 \pm 92.53$ & $95.41 \pm 68.42$ & 0.834 \\
\hline \multicolumn{4}{|l|}{ No. of anterior levels fused } \\
\hline 1 & 67 & 20 & \\
\hline 2 & 53 & 7 & \\
\hline 3 & 15 & 7 & \\
\hline 4 & 19 & 3 & \\
\hline 5 & 1 & 0 & \\
\hline $\begin{array}{l}\text { Mean no. of anterior fusion } \\
\text { levels }\end{array}$ & $1.93 \pm 1.039$ & $1.81 \pm 1.023$ & 0.534 \\
\hline Approach-related sequelae & & & 0.996 \\
\hline No & $134(86.5 \%)$ & $32(86.5 \%)$ & \\
\hline Yes & $21(13.5 \%)$ & $5(13.5 \%)$ & \\
\hline Complications & & & 0.544 \\
\hline No & $144(82.9 \%)$ & $36(97.3 \%)$ & \\
\hline Yes & $11(7.1 \%)$ & $1(2.7 \%)$ & \\
\hline
\end{tabular}

Values are presented as the number $(\%)$ or as the mean \pm SD.

Similar conclusions have also been reported for anterior lumbar interbody fusion (ALIF). ${ }^{17-19}$ Functional outcomes have also been reported to be similar between obese and nonobese patients. ${ }^{5,9,18}$ However, because of the two separate approaches to the spine and the separate skin incisions when including L5-S1 (as opposed to single incision for an ALIF), we did find a statistically significant

TABLE 2. Medical and surgical complications of nonobese and obese patients

\begin{tabular}{lcccc}
\hline \multicolumn{1}{c}{ Variable } & Both Cohorts & Nonobese $(\mathrm{BMI}<30)$ & Obese $(\mathrm{BMI} \geq 30)$ & $\mathrm{p}$ Value \\
\hline Approach-related sequelae & 37 & 21 & 16 & 0.309 \\
Transient left thigh/leg numbness & 16 & 9 & 7 & \\
Transient left thigh/leg weakness & 6 & 5 & 1 & \\
Transient left thigh/leg pain & 14 & 6 & 8 & \\
Left abdomen incisional pain & 1 & 1 & 0 & \\
\hline Medical complications & 12 & 3 & 6 & 0.532 \\
Ileus & 4 & 1 & 1 & \\
DVT & 2 & 2 & 1 & \\
Urinary retention & 5 & 0 & 3 & \\
lliac vein tear & 1 & 5 & 0 & \\
\hline Wound complications & 5 & 4 & 0 & \\
Left psoas hematoma & 4 & 1 & 0 & \\
Left psoas abscess & 1 & & 0.098 \\
\hline
\end{tabular}

DVT = deep vein thrombosis. 
TABLE 4. Subgroup analysis of patients undergoing at least one level of OLIF from L1 to L5 and also L5-S1

\begin{tabular}{|c|c|c|c|}
\hline Variable & $\begin{array}{l}\text { Nonobese (BMI } \\
<30, n=53)\end{array}$ & $\begin{array}{l}\text { Obese (BMl } \\
\geq 30, n=24)\end{array}$ & $\begin{array}{c}\mathrm{p} \\
\text { Value }\end{array}$ \\
\hline Age & $65.15 \pm 11.81$ & $60.38 \pm 13.02$ & 0.116 \\
\hline Sex & & & 0.092 \\
\hline Male & 14 & 11 & \\
\hline Female & 39 & 13 & \\
\hline Smoker & & & 0.424 \\
\hline No & 48 & 23 & \\
\hline Yes & 5 & 1 & \\
\hline Follow-up time (mos) & $14.15 \pm 9.79$ & $18.88 \pm 9.97$ & 0.055 \\
\hline Surgical time (mins) & $223.55 \pm 57.93$ & $273.75 \pm 90.07$ & 0.004 \\
\hline $\mathrm{EBL}(\mathrm{ml})$ & $101.42 \pm 109.68$ & $84.382 \pm 57.02$ & 0.476 \\
\hline \multicolumn{4}{|l|}{ Levels of anterior fusion } \\
\hline L4-S1 & 26 & 9 & \\
\hline L3-S1 & 8 & 9 & \\
\hline L2-S1 & 18 & 6 & \\
\hline L1-S1 & 1 & 0 & \\
\hline $\begin{array}{l}\text { Mean no. of anterior levels } \\
\text { fused }\end{array}$ & $2.89 \pm 0.954$ & $2.88 \pm 0.797$ & 0.955 \\
\hline Approach-related sequelae & & & 0.039 \\
\hline No & $46(86.8 \%)$ & $16(66.7 \%)$ & \\
\hline Yes & $7(13.2 \%)$ & $8(33.3 \%)$ & \\
\hline Complications & & & 0.876 \\
\hline No & $48(90.6 \%)$ & $22(91.7 \%)$ & \\
\hline Yes & $5(9.4 \%)$ & $2(8.3 \%)$ & \\
\hline
\end{tabular}

Values are presented as the number (\%) or as the mean \pm SD.

increase in approach-related sequelae and longer operative times when the L5-S1 level was included in obese patients compared to nonobese patients. Because the L5-S1 level requires a separate incision and a separate surgical approach distinct from those for L1 to L5, it essentially subjects the patient to two small, separate surgeries at once. This distinction is probably what separates our findings from historic ALIF studies and from our results when only assessing OLIF morbidity at L1-5. In our study, the obese group (between L1-5, including L5-S1) had a mean operative time that was 50 minutes longer than that seen in the nonobese group, and this may be because the increased adipose tissue can make visualization more difficult and require additional time to gain adequate exposure. ${ }^{20}$

Transient sensorimotor symptoms in the ipsilateral thigh remain the most common sequelae after lateral lumbar interbody fusion (LLIF). It has been shown that approximately $30 \%-40 \%$ of patients have this temporary phenomenon, but permanent symptoms lasting more than 6 months affect only 4\%-5\% of LLIF cases. ${ }^{21}$ In their meta-analysis of 6481 LLIF patients (transpsoas and prepsoas), Walker et al. found that the transpsoas group had a higher rate of transient sensory symptoms, transient hip flexor weakness, and permanent neurological weakness, but a higher rate of sympathetic nerve injury than was seen in the prepsoas group. ${ }^{22}$ With regard to previously published reports on OLIF and approach-related sequelae, the rates of transient neurological symptoms have been re-
TABLE 5. Demographic and procedural data of patients undergoing L5-S1 OLIF only

\begin{tabular}{lccc}
\hline \multicolumn{1}{c}{ Variable } & $\begin{array}{c}\text { Nonobese (BMI } \\
<30, \mathrm{n}=15)\end{array}$ & $\begin{array}{c}\text { Obese (BMI } \\
\geq 30, \mathrm{n}=9)\end{array}$ & $\begin{array}{c}\mathrm{p} \\
\text { Value }\end{array}$ \\
\hline Age & $56.93 \pm 17.96$ & $52.22 \pm 16.06$ & 0.525 \\
\hline $\begin{array}{l}\text { Sex } \\
\quad \text { Male }\end{array}$ & 4 & & 0.728 \\
$\quad$ Female & 11 & 6 & \\
\hline $\begin{array}{l}\text { Smoker } \\
\text { No }\end{array}$ & 13 & & 0.572 \\
$\quad$ Yes & 2 & 2 & \\
\hline Follow-up time (mos) & $16.87 \pm 8.78$ & $15.56 \pm 9.36$ & 0.733 \\
\hline Surgical time (mins) & $164.93 \pm 70.35$ & $169.56 \pm 73.18$ & 0.879 \\
\hline EBL (ml) & $83.33 \pm 52.33$ & $55.56 \pm 16.67$ & 0.139 \\
\hline Approach-related sequelae & & & 0.265 \\
$\quad$ No & $14(93.3 \%)$ & $7(77.8 \%)$ & \\
$\quad$ Yes & $1(6.7 \%)$ & $2(22.2 \%)$ & \\
\hline Complications & & & 0.088 \\
$\quad$ No & $13(86.7 \%)$ & $5(55.6 \%)$ & \\
$\quad$ Yes & $2(13.3 \%)$ & $4(44.4 \%)$ & \\
\hline
\end{tabular}

Values are presented as the number (\%) or as the mean \pm SD.

ported to range from $6.1 \%$ to $21.4 \% .^{12,13,23}$ With regard to LLIF versus OLIF, there are advantages and disadvantages to each. Proponents of the prepsoas approach posit that entering the interbody space anterior to the psoas muscle avoids direct trauma to the lumbar plexus within the muscle, to the nerves on the surface of the muscle (genitofemoral, iliohypogastric), and to the muscle itself. However, it should be noted that the risk of neurological injury is not completely obviated with a prepsoas approach. This likely relates to the fact that some dorsal retraction of the psoas muscle is typically required during the orthogonal graft rotation from an oblique angle to a true lateral angle in order to place the graft in a lateral orientation. Additionally, the oblique trajectory places the contralateral neural foramen at risk if instruments are inadvertently advanced too far during maneuvers to release the contralateral annulus fibrosus. Working slightly anterior to the psoas also places adjacent anatomical structures at risk. The risk of major vascular injury has been reported to be nearly five times higher for the prepsoas-approach group than for the transpsoas-approach group. ${ }^{22}$

In our cohort, there was no significant difference in expected approach-related sequelae when comparing patients with BMI $\geq 30 \mathrm{~kg} / \mathrm{m}^{2}$ and patients with $\mathrm{BMI}<30$ $\mathrm{kg} / \mathrm{m}^{2}$, but in the subgroup analysis of patients with multilevel OLIF between L1 and L5, inclusive of L5-S1, the obese group had more anticipated approach-related sequelae than the nonobese group. These sequelae are likely a reflection of increased retraction because of the surrounding tissue for visualization and increased operative time. This increased retraction for visualization in obese patients over multiple areas of the lumbar plexus may also have resulted in the increased approach-related sequelae. However, these differences between obese and nonobese patients were only seen in patients with multilevel OLIF when the L5-S1 segment was included, not in the patients 
TABLE 6. Demographic and procedural data for patients who underwent OLIF from L1 to L5 excluding L5-S1

\begin{tabular}{|c|c|c|c|}
\hline Variable & $\begin{array}{c}\text { Nonobese } \\
(\mathrm{BMI}<30 \\
\mathrm{n}=87)\end{array}$ & $\begin{array}{c}\text { Obese } \\
(\mathrm{BMI} \geq 30 \\
n=50)\end{array}$ & $\begin{array}{c}\mathrm{p} \\
\text { Value }\end{array}$ \\
\hline Age & $65.40 \pm 10.20$ & $62.44 \pm 13.69$ & 0.152 \\
\hline Sex & & & 0.155 \\
\hline Male & 44 & 19 & \\
\hline Female & 43 & 31 & \\
\hline Smokers & & & 0.414 \\
\hline No & 83 & 46 & \\
\hline Yes & 4 & 4 & \\
\hline Follow-up time (mos) & $18.14 \pm 12.87$ & $16.86 \pm 10.47$ & 0.551 \\
\hline Surgical time (mins) & $161.55 \pm 71.62$ & $160.34 \pm 66.68$ & 0.922 \\
\hline $\mathrm{EBL}(\mathrm{ml})$ & $87.76 \pm 86.75$ & $87.60 \pm 65.91$ & 0.991 \\
\hline \multicolumn{4}{|l|}{ No. of anterior fusion levels } \\
\hline 1 & 52 & 33 & \\
\hline 2 & 27 & 12 & \\
\hline 3 & 7 & 4 & \\
\hline 4 & 1 & 1 & \\
\hline 5 & 0 & 0 & \\
\hline $\begin{array}{l}\text { Mean no. of anterior levels } \\
\text { fused }\end{array}$ & $1.51 \pm 0.697$ & $1.46 \pm 0.734$ & 0.717 \\
\hline Approach-related sequelae & & & 0.631 \\
\hline No & $74(85.1 \%)$ & $44(88.0 \%)$ & \\
\hline Yes & $13(14.9 \%)$ & $6(12.0 \%)$ & \\
\hline Complications & & & 0.655 \\
\hline No & $82(94.3 \%)$ & $48(96.0 \%)$ & \\
\hline Yes & $5(5.7 \%)$ & $2(4.0 \%)$ & \\
\hline
\end{tabular}

Values are presented as the number (\%) or as the mean $\pm \mathrm{SD}$.

who only had surgeries between L1 and L5, indicating that the second surgical approach to the L5-S1 level could have increased the morbidity because of the obesity.

There are a number of limitations with this study. First, this is a retrospective, single-institution study. Also, a minimum of 2 years of follow-up would have been ideal, but since this study focused on perioperative morbidity, most operative factors should have been captured with the follow-up in this study. Thus, perioperative morbidity would have been observed within 90 days-well within the median follow-up period-even though there are different median follow-up times in the two groups. Because we did not have a minimum of 2-year follow-up period, we did not evaluate long-term complications such as subsidence, pseudarthrosis, and other complications that are only seen with long-term follow-up. Thus, we only detected complications related to cage failure or migration if the patient had revision surgery within the follow-up period; otherwise, these long-term complications were beyond the scope of this study. Another limitation is that the retrospective nature of this study may result in underreporting of complications. One way that we have tried to mitigate this shortcoming was to have consistent follow-up visits among the surgeons. At our spine center, the patients are seen at 1 , $3,6,12$, and 24 months for all of the spine surgeons. Thus, there is a consistent follow-up among the surgeons, which helps diminish the incidence of underreported complications. Moreover, by focusing on the perioperative nature within this study (a 90-day window), we hoped to further decrease this underreporting phenomenon because more patients are inclined to attend follow-up visits within a shorter time period. Another limitation to this study is that there may be a selection bias. Obese patients may have been selected to undergo other modalities, such as ALIF or posterior fusion, in order to avoid the large abdominal approach. This should be considered when interpreting these data. Another factor is that the reality of modern obesity has probably shifted more toward a BMI $35 \mathrm{~kg} / \mathrm{m}^{2}$, not 30 $\mathrm{kg} / \mathrm{m}^{2}$, and we had fewer patients in the category of BMI $\geq 35 \mathrm{~kg} / \mathrm{m}^{2}$. Thus, the study may have been underpowered to detect true differences in patient with a BMI of $\geq 35$ $\mathrm{kg} / \mathrm{m}^{2}$. Also, we did not analyze the long-term functional status of these patients; it would have been ideal to assess whether the increased morbidity in obese patients affected long-term outcomes. Finally, many of the approach-related sequelae noted in this study were expected, transient sequelae (such as thigh symptoms). However, because we found these sequelae were nonetheless higher in obese patients, it is something to consider when counseling obese patients about surgery.

\section{Conclusions}

Although obesity generally does not increase approachrelated sequelae and complications during OLIF, when multilevel OLIF includes the L5-S1 level, patients have longer operative times and a higher incidence of transient, approach-related sequelae. Thus, obese patients should be warned of possible higher rates of approach-related sequelae when considering multilevel OLIF inclusive of L5-S1.

\section{References}

1. Cawley J, Meyerhoefer C. The medical care costs of obesity: an instrumental variables approach. J Health Econ. 2012;31(1):219-230.

2. Finkelstein EA, Trogdon JG, Cohen JW, Dietz W. Annual medical spending attributable to obesity: payer-and servicespecific estimates. Health Aff (Millwood). 2009;28(5):w822w831.

3. Bagley C, MacAllister M, Dosselman L, et al. Current concepts and recent advances in understanding and managing lumbar spine stenosis. F1000 Res. 2019;8(F1000 Faculty Rev): 137.

4. Shepard N, Cho W. Recurrent lumbar disc herniation: a review. Global Spine J. 2019;9(2):202-209.

5. Goyal A, Elminawy M, Kerezoudis P, et al. Impact of obesity on outcomes following lumbar spine surgery: a systematic review and meta-analysis. Clin Neurol Neurosurg. 2019;177:27-36.

6. Cao J, Kong L, Meng F, et al. Impact of obesity on lumbar spinal surgery outcomes. J Clin Neurosci. 2016;28:1-6.

7. Epstein NE. More risks and complications for elective spine surgery in morbidly obese patients. Surg Neurol Int. 2017;8:66.

8. Lingutla KK, Pollock R, Benomran E, et al. Outcome of lumbar spinal fusion surgery in obese patients: a systematic review and meta-analysis. Bone Joint J. 2015;97-B(10):13951404.

9. Wang T, Han C, Jiang H, Tian P. The effect of obesity on 
clinical outcomes after minimally invasive surgery of the spine: a systematic review and meta-analysis. World Neurosurg. 2018;110:e438-e449.

10. Mobbs RJ, Phan K, Malham G, et al. Lumbar interbody fusion: techniques, indications and comparison of interbody fusion options including PLIF, TLIF, MI-TLIF, OLIF/ATP, LLIF and ALIF. J Spine Surg. 2015;1(1):2-18.

11. Phan K, Maharaj M, Assem Y, Mobbs RJ. Review of early clinical results and complications associated with oblique lumbar interbody fusion (OLIF). J Clin Neurosci. 2016;31:23-29.

12. Quillo-Olvera J, Lin GX, Jo HJ, Kim JS. Complications on minimally invasive oblique lumbar interbody fusion at L2-L5 levels: a review of the literature and surgical strategies. Ann Transl Med. 2018;6(6):101.

13. Xu DS, Walker CT, Godzik J, et al. Minimally invasive anterior, lateral, and oblique lumbar interbody fusion: a literature review. Ann Transl Med. 2018;6(6):104.

14. James PT, Leach R, Kalamara E, Shayeghi M. The worldwide obesity epidemic. Obes Res. 2001;9(suppl 4):228S-233S.

15. DiGiorgio AM, Edwards CS, Virk MS, et al. Stereotactic navigation for the prepsoas oblique lateral lumbar interbody fusion: technical note and case series. Neurosurg Focus. 2017;43(2):E14.

16. Abbasi H, Grant A. Effect of body mass index on perioperative outcomes in minimally invasive oblique lateral lumbar interbody fusion versus open fusions: a multivariant analysis. Cureus. 2018;10(3):e2288.

17. Katz AD, Mancini N, Karukonda T, et al. Approach-based comparative and predictor analysis of 30-day readmission, reoperation, and morbidity in patients undergoing lumbar interbody fusion using the ACS-NSQIP dataset. Spine (Phila Pa 1976). 2019;44(6):432-441.

18. Phan K, Rogers P, Rao PJ, Mobbs RJ. Influence of obesity on complications, clinical outcome, and subsidence after anterior lumbar interbody fusion (ALIF): prospective observational study. World Neurosurg. 2017;107:334-341.

19. Upadhyayula PS, Curtis EI, Yue JK, et al. Anterior versus transforaminal lumbar interbody fusion: perioperative risk factors and 30-day outcomes. Int J Spine Surg. 2018;12(5):533-542.

20. Zairi F, Sunna TP, Westwick HJ, et al. Mini-open oblique lumbar interbody fusion (OLIF) approach for multi-level discectomy and fusion involving L5-S1: preliminary experience. Orthop Traumatol Surg Res. 2017;103(2):295-299.
21. Hah R, Kang HP. Lateral and oblique lumbar interbody fusion-current concepts and a review of recent literature. Curr Rev Musculoskelet Med. 2019;12:305-310.

22. Walker CT, Farber SH, Cole TS, et al. Complications for minimally invasive lateral interbody arthrodesis: a systematic review and meta-analysis comparing prepsoas and transpsoas approaches. J Neurosurg Spine. 2019;30:446-460.

23. Woods KR, Billys JB, Hynes RA. Technical description of oblique lateral interbody fusion at L1-L5 (OLIF25) and at L5-S1 (OLIF51) and evaluation of complication and fusion rates. Spine J. 2017;17(4):545-553.

\section{Disclosures}

Dr. Burch reports being a consultant for Medtronic. Dr. Chou reports being a consultant for Medtronic and Globus; he receives royalties from Globus. Dr. Mummaneni reports being a consultant for DePuy Spine, Globus, and Stryker; he owns stock in Spinicity/ ISD; he receives support for non-study-related clinical or research efforts that he oversees from NREF and from AOSpine; and he receives royalties from DePuy Spine, Thieme Publishers, and Springer Publishers.

\section{Author Contributions}

Conception and design: Burch, Chou. Acquisition of data: Xi. Analysis and interpretation of data: Xi. Drafting the article: Burch, Mummaneni, Eichler. Critically revising the article: Mummaneni, Eichler. Reviewed submitted version of manuscript: Mayer. Statistical analysis: Mayer. Administrative/technical/ material support: Chou. Study supervision: Chou.

\section{Supplemental Information}

Online-Only Content

Supplemental material is available with the online version of the article.

Supplemental Figure 1. https://thejns.org/doi/suppl/10.3171/ 2020.1.SPINE191131.

\section{Correspondence}

Zhuo Xi: Shengjing Hospital of China Medical University, Liaoning Sheng, China. neurosurgeon-xz@hotmail.com. 